\title{
Canine Lung Adenocarcinoma
}

National Cancer Institute

\section{Source}

National Cancer Institute. Canine Lung Adenocarcinoma. NCI Thesaurus. Code C129299.

A carcinoma that arises from the lung in dogs and is characterized by the presence of malignant glandular epithelial cells. 